\title{
Research
}

\section{The diagnostic value of symptoms for colorectal cancer in primary care:}

\author{
a systematic review
}

\begin{abstract}
Background

Over 37000 new colorectal cancers are diagnosed in the UK each year. Most present symptomatically to primary care.

Aim

To conduct a systematic review of the diagnostic value of symptoms associated with colorectal cancer.

Design

Systematic review.

\section{Method}

MEDLINE, Embase, Cochrane Library, and CINAHL were searched to February 2010, for diagnostic studies of symptomatic adult patients in primary care. Studies of asymptomatic patients, screening, referred populations, or patients with colorectal cancer recurrences, or with fewer than 100 participants were excluded. The target condition was colorectal cancer. Data were extracted to estimate the diagnostic performance of each symptom or pair of symptoms. Data were pooled in a meta-analysis. The quality of studies was assessed with the QUADAS tool.

\section{Results}

Twenty-three studies were included. Positive predictive values (PPVs) for rectal bleeding from 13 papers ranged from $2.2 \%$ to $16 \%$, with a pooled estimate of $8.1 \% 195 \%$ confidence interval $[\mathrm{Cl}]=6.0 \%$ to $11 \%$ ) in those aged $\geq 50$ years. Pooled PPV estimates for other symptoms were: abdominal pain (three studies) $3.3 \%(95 \% \mathrm{Cl}=0.7 \%$ to $16 \%)$; and anaemia (four studies) $9.7 \%(95 \% \mathrm{Cl}=3.5 \%$ to $27 \%)$. For rectal bleeding accompanied by weight loss or change in bowel habit, pooled positive likelihood ratios (PLRs) were $1.9(95 \% \mathrm{Cl}=1.3$ to 2.8$)$ and 1.8 $(95 \% \mathrm{Cl}=1.3$ to 2.5$)$ respectively, suggesting

\section{INTRODUCTION}

Colorectal cancer is the third most common cancer in the UK, with over 37000 new diagnoses each year. A national screening programme is operative, but will only identify a minority of cancers, with the majority presenting symptomatically to primary care. ${ }^{1}$ Many symptoms have been described, with the main ones being rectal bleeding, diarrhoea, or constipation collectively sometimes named 'change in bowel habit' - loss of weight, abdominal pain, and anaemia. ${ }^{2}$ However, these symptoms are also common with benign conditions, so the clinician has to select patients at higher risk for investigation. There is no test available for use in primary care that has sufficient discrimination to provide the basis for referral decisions, although primary care investigation sometimes includes faecal occult blood testing and estimation of haemoglobin.

The decision to refer for investigation is largely based on the estimated risk of an underlying colorectal cancer. Risk estimates underpin national guidance, such as the Referral Guidelines for Suspected Cancer, first published in 2000 and updated in $2005 .{ }^{3}$ This guidance was based on a literature review of both primary studies and review papers. However, at that time almost all published research was based on findings in the referred population, and so does not pertain to the primary care population,
\end{abstract} higher risk when both symptoms were present Conversely, the PLR was one or less for abdominal pain, diarrhoea, or constipation accompanying rectal bleeding.

\section{Conclusion}

The findings suggest that investigation of rectal bleeding or anaemia in primary care patients is warranted, irrespective of whether other symptoms are present. The risks from other single symptoms are lower, though multiple symptoms also warrant investigation.

\section{Keywords}

colorectal neoplasms; diagnosis; primary health care; review, systematic; symptoms.
M Astin, research associate, MSc BSc; T Griffin, MSc, BSc, research associate; W Hamilton, MD, FRCP, FRCGP, visiting fellow, University of Bristol, Academic Unit of Primary Health Care, Bristol. RD Neal, PhD, FRCGP, senior lecturer, North Wales Clinical School, Department of Primary Care \& Public Health, School of Medicine, Cardiff University, Wrexham. PW Rose, MB, BChir, FRCGP, lecturer, University of Oxford, Department of Primary Health Care, Old Road Campus, Oxford.

Address for correspondence William Hamilton, National School of Primary where the advice is to be applied. This criticism applies to a previous systematic review that examined all studies together from different populations. ${ }^{4}$ Another review included both populations but differed in focus. ${ }^{5}$ Additionally, much progress has been made in quantifying the risk of cancer in primary care. Thus, a systematic review was performed to identify the risk of colorectal cancer in patients reporting a symptom to primary care.

\section{METHOD}

\section{Data sources and search strategy}

Comprehensive searches of electronic databases were conducted in MEDLINE (1950 to April 2009). Embase (1980 to April 2009), and MEDLINE in process (April 2009) using the OVID platform. The Cochrane Library (Database of Reviews of Effectiveness, Cochrane Database of Systematic Reviews, Cochrane Controlled Trials Register Issue 2 April 2009) and CINAHL (1998 to April 2009) were searched using the Wiley interface. All searches were updated in February 2010. Diagnostic terms were used along with study design terms to identify potentially relevant study types; terms to identify lower gastrointestinal neoplasia; terms to identify symptoms common in colorectal cancer, for example, rectal bleeding, weight loss, rectal or abdominal pain or mass, anaemia, constipation or diarrhoea; and terms for
Care Research, Academic Unit of Primary Health Care, Department of Community Based Medicine, 25-27 Belgrave Road, Bristol, BS8 4AA.

E-mail: W.T.Hamiltonabtopenworld.com

Submitted: 27 July 2010; Editor's response: 7 September 2010; final acceptance: 22 October 2010

CBritish Journal of General Practice This is the full-length article (published online 26 Apr 2011) of an abridged version published in print. Cite this article as: Br J Gen Pract 2011; DOI: 10.3399/bjgp11X572427. 


\section{How this fits in}

The symptoms of colorectal cancer have been described in many secondary and primary care studies. The risk of colorectal cancer in primary care patients with symptoms has been estimated in single studies. Risks from secondary care studies do not pertain to primary care populations, and generally overestimate the likelihood of a cancer as the cause of symptoms. The pooled positive predictive value of colorectal cancer with rectal bleeding was $8.1 \%$ in the over 50 s, irrespective of other symptoms. Second symptoms accompanying rectal bleeding altered the strength of the association with cancer: weight loss or a change in bowel habit increased the risk further, whereas abdominal pain decreased the overall risk. Anaemia was also a high-risk symptom with a pooled positive predictive value of $9.7 \%$, though there were too few studies to offer pooled estimates for specific levels of haemoglobin.

primary care settings Synonyms and spelling variations of these terms were used. All sets included Medical Subject Heading (MeSH) and free-text terms, and there were no language restrictions. The search strategy is available from the authors.

Further searches of ongoing studies included the European Organisation for Research and Treatment of Cancer, National Cancer Institute of Canada Clinical Trials Group, Cancer Research UK Directory of Funded Research, and the National Cancer Research Network. Reference lists of included studies were screened for relevance; personal literature collections and contacts of authors were also used.

\section{Inclusion criteria}

Studies of any design were eligible. These included randomised trials and retrospective or prospective observational studies such as cohort and case-control designs. Only adult populations of symptomatic individuals were of interest; however, if younger patients were participants, these studies were also included. Only studies conducted within primary care were eligible, including those utilising electronic general practice databases and those undergoing primary care-based investigations.
Exclusions were studies of asymptomatic participants attending for screening or population studies, those already referred to secondary care, or patients with recurrent colorectal cancer. Studies recruiting fewer than 100 participants were excluded, as they would provide very few cancers.

The target condition was adenocarcinoma of the colon or rectum, including carcinoma in situ. The methodology used in this review was that of diagnostic accuracy, using symptoms commonly reported by patients with colorectal cancer as index 'tests'. Symptoms had to be adequately reported, for example, as abdominal pain not discomfort. They could be recorded by the clinician, collected using a questionnaire, or coded, for example, with the International Classification of Primary Care. ${ }^{6}$ Valid reference standards included histology, colonoscopy, double-contrast barium enema, computerised tomography colonography, or clinical follow-up of 1 year or more.

\section{Study selection}

One reviewer ran the searches and screened titles and abstracts for inclusion. All potentially relevant included abstracts were then screened blind by another author, and the findings compared. Any disagreements were resolved by consensus; if uncertainty remained, the full paper was obtained to assess its eligibility. Authors were contacted for further information when necessary.

\section{Data extraction and quality assessment}

Data extraction and quality assessment of full papers were conducted by one reviewer. Data extraction was checked by a second reviewer. Review Manager (Version 5.0) was used for data collation, and methodological quality was assessed with the QUADAS tool. ${ }^{7}$ Stata (version 10) was used to summarise positive predictive values (PPVs) and to plot Forest and likelihood ratio graphs. Other diagnostic performance measures were analysed in Meta-DiSc. ${ }^{8}$ One question was added to the QUADAS instrument about the description of symptoms, and two questions removed: blinding of the reference standard; and the presence of clinical information for interpretation of reference tests /symptoms were used as a 'test', and it was assumed 
that clinical information was available).

\section{Statistical analysis and data synthesis}

The number of true and false positives and true and false negatives were extracted from each study. If only data on true and false positives were available, as in some studies of patients with rectal bleeding, the PPV was calculated. Where all data for a $2 x$ 2 table were available in three or more studies, positive and negative likelihood ratios (PLRs, NLRs) were calculated (Cochrane Handbook for Systematic Reviews of Interventions Version 4.2.6 2006). Case-control studies were not used in the assessment of PPV because of potential bias associated with this research design.., 10 Inconsistency between studies for each metric was measured by the $R$ statistic and categorised as low (0\% to $25 \%$ ), moderate (30\% to $60 \%$ ), substantial (50\% to $90 \%$ ), or considerable $(75 \%$ to $100 \%)$. Tests for heterogeneity were based on $\chi^{2}$ and the $R$ statistic, with $P$-values $<0.10$ taken to be statistically significant. Random effects models were used for summary and subgroup statistics.

Data were extracted for each relevant symptom and for pairs of symptoms. The effect of age of participants as a subgroup was also examined across all studies where possible. Other subgroup analyses considered were: sample size $k<1000$ versus $\geq 1000)$; number of cancers detected $(<100$ versus $\geq 100$ ); single-centre recruitment versus multicentre recruitment; case-control versus cohort designs; data collection by template or questionnaire versus consultation; and studies of firstonset only rectal bleeding versus all times of onset. The effects of quality criteria were assessed by comparing the findings of studies that met the criteria with those that were either not met or unclear when significant heterogeneity was present between studies.

\section{RESULTS}

The electronic searches identified 2097 records; a further 11 were retrieved from reference lists, and four from personal collections. Fifty-seven papers were obtained for appraisal; 23 met the inclusion criteria, including one identified from reference list screening (Appendix 1). A total of 81464 participants were recruited. Study characteristics are shown in Appendix 2.
The majority of studies were conducted in Europe ( $n=21)$, with one each in Australia and the US. Study sizes ranged from 112 to 933 in prospective designs, and from 130 to 43791 in retrospective designs. Symptom data were collected using a questionnaire or template for patients or doctors in nine studies. In eight, the method of data collection was not described, or the routine process was used in GPs' surgeries; in six retrospective studies, symptom data were retrieved from NHS databases. Another study used GP records. Four of 15 papers reported first-onset rectal bleeding. In one study, GPs had recently undertaken a training programme in colorectal diseases. ${ }^{11}$ Only three studies were conducted in a single centre. ${ }^{12-14}$

The proportion of study participants with colorectal cancer ranged from $0.4 \%$ to $23.2 \%$, with 17 studies having $10 \%$ or less. The symptoms reported singly were: rectal bleeding ( $n=15$ studies), abdominal pain ( $n$ $=5$ studies), anaemia ( $n=5$ studies), weight loss ( $n=3$ studies), diarrhoea $(n=3$ studies), constipation ( $n=3$ studies), change in bowel habit ( $n=2$ studies), and bloating ( $n$ $=1$ study). Two papers reported colorectal cancers from any of several symptoms rather than specific symptoms.15,16 Symptom pairs were reported in six papers.

\section{Rectal bleeding}

Studies reported rectal bleeding as either a single symptom, or subclassified by appearance. Some studies included only patients with a first rectal bleed. ${ }^{12,17-19}$ All data on rectal bleeding were grouped together. Sufficient data to calculate PPVs for rectal bleeding were available in 13 papers with 18634 participants. 11,12,14,17-26 This is displayed as a Forest plot (Figure 1A). The PPV ranged from $2.2 \%{ }^{18}$ to $15.8 \% .^{11} \mathrm{~A}$ subgroup analysis of five studies with data from 887 patients over 50 years of age (Figure 1B) provided a pooled estimate of $8.1 \%(95 \%$ confidence interval $[\mathrm{Cl}]=6.0$ to 10.8), with moderate inconsistency between studies $(R=31 \%, P=0.21) .17,21,24-26$ Data were pooled in three studies of rectal bleeding with 46164 patients. ${ }^{11,27,28}$ However, a large degree of inconsistency $(R>96.0 \%, P<0.001)$ was present (Table 1).

Participants in the six studies reporting symptom pairs all examined rectal bleeding with a second symptom; these are described next. ${ }^{19-21,22-24}$ 
Table 1. Sensitivity, specificity, positive and negative likelihood ratios of unpaired symptoms

\begin{tabular}{|c|c|c|c|c|}
\hline Symptom and study & $\begin{array}{l}\text { Sensitivity, } \\
\%(95 \% \mathrm{Cl})\end{array}$ & $\begin{array}{l}\text { Specificity, } \\
\%(95 \% \text { CI })\end{array}$ & $\begin{array}{l}\text { Positive likelihood } \\
\text { ratio }(95 \% \mathrm{CI})\end{array}$ & $\begin{array}{l}\text { Negative likelihood } \\
\text { ratio }(95 \% \mathrm{Cl})\end{array}$ \\
\hline \multicolumn{5}{|l|}{ Rectal bleeding } \\
\hline Hamilton et al, $2005^{27}$ & $42(37.2$ to 47.8$)$ & 96 (94.8 to 96.7$)$ & 10.13 (7.85 to 13.08 ) & 0.60 (0.55 to 0.66$)$ \\
\hline Hamilton et al, $2009^{28}$ & $16(14.6$ to 16.6$)$ & 99 (98.7 to 98.9) & $12.97(11.62$ to 14.48$)$ & 0.85 (0.84 to 0.86$)$ \\
\hline Panzuto et al, 2003"11 & 44 (28.5 to 60.3 ) & $60(53.3$ to 66.1$)$ & 1.09 (0.75 to 1.60$)$ & 0.94 (0.70 to 1.25$)$ \\
\hline \multirow[t]{2}{*}{ Summary estimates } & $17(16.4$ to 18.4$)$ & 98 (98.3 to 98.6$)$ & 5.31 (1.65 to 17.07$)$ & 0.77 (0.57 to 1.03 ) \\
\hline & $R=98.6 \%, P<0.001$ & $R=99.6 \%, P<0.001$ & $R=98.7 \%, P<0.001$ & $R=96.7 \%, P<0.001$ \\
\hline \multicolumn{5}{|l|}{ Abdominal pain } \\
\hline Hamilton et al, $2005^{27}$ & $42(37.2$ to 47.8 ) & 91 (89.2 to 92.0) & 4.54 (3.75 to 5.49$)$ & 0.64 (0.58 to 0.70$)$ \\
\hline Hamilton et al, $2009^{28}$ & 30 (28.5 to 31.0 ) & $92(91.6$ to 92.1 ) & 3.65 (3.46 to 3.85 ) & 0.77 (0.75 to 0.78$)$ \\
\hline Panzuto et al, 2003'11 & 73 (57.1 to 85.8 ) & 19 (14.4 to 24.8$)$ & $0.91(0.75$ to 1.10$)$ & 1.39 (0.79 to 2.46$)$ \\
\hline \multirow{2}{*}{ Summary estimates } & 31 (29.6 to 32.0 ) & 91 (91.1 to 91.6 ) & $2.47(1.09$ to 5.61$)$ & 0.75 (0.62 to 0.90$)$ \\
\hline & $R=96.4 \%, P<0.001$ & $R=99.7 \% P<0.001$ & $R=99.0 \%, P<0.001$ & $R=89.9 \%, P<0.001$ \\
\hline \multicolumn{5}{|l|}{ Weight loss } \\
\hline Hamilton et al, $2005^{27}$ & 27 (22.3 to 31.9) & 95 (93.6 to 95.7) & 5.11 (3.92 to 6.65 ) & 0.77 (0.72 to 0.82 ) \\
\hline Hamilton et al, $2009^{28}$ & 10 (9.5 to 11.1$)$ & 96 (95.8 to 96.2 ) & 2.57 (2.34 to 2.81$)$ & 0.94 (0.93 to 0.94$)$ \\
\hline Panzuto et al, 2003'11 & 37 (22.1 to 53.1$)$ & 89 (84.0 to 92.4 ) & 3.24 (1.89 to 5.54$)$ & $0.72(0.56$ to 0.91$)$ \\
\hline \multirow[t]{2}{*}{ Summary estimates } & 11 (10.6 to 12.3 ) & $96(95.7$ to 96.1$)$ & 3.48 (2.08 to 5.80$)$ & 0.82 (0.69 to 0.97$)$ \\
\hline & $R=97.7 \%, P<0.001$ & $R=93.0 \%, P<0.001$ & $R=91.6 \%, P<0.001$ & $R=95.1 \%, P<0.001$ \\
\hline \multicolumn{5}{|l|}{ Diarrhoea } \\
\hline Hamilton et al, $2005^{27}$ & 38 (32.7 to 43.1$)$ & 90 (88.7 to 91.6$)$ & 3.86 (3.17 to 4.69 ) & 0.69 (0.63 to 0.75$)$ \\
\hline Hamilton et al, $2009^{28}$ & $18(17.0$ to 19.1$)$ & $94(94.1$ to 94.6 ) & 3.18 (2.97 to 3.41$)$ & 0.87 (0.86 to 0.88 ) \\
\hline Panzuto et al, 2003'11 & 24 (12.4 to 40.3 ) & 69 (62.3 to 74.4 ) & 0.78 (0.44 to 1.37$)$ & $1.10(0.91$ to 1.34$)$ \\
\hline \multirow[t]{2}{*}{ Summary estimates } & 19 (18.3 to 20.3) & 94 (93.8 to 94.2 ) & 2.44 (1.57 to 3.79$)$ & 0.86 (0.70 to 1.04$)$ \\
\hline & $R=97.2 \%, P<0.001$ & $R=99.0 \%, P<0.001$ & $R=92.7 \%, P<0.001$ & $R=94.4 \%, P<0.001$ \\
\hline \multicolumn{5}{|l|}{ Constipation } \\
\hline Hamilton et al, $2005^{27}$ & 26 (21.5 to 31.0$)$ & 85 (83.5 to 86.8 ) & $1.76(1.43$ to 2.17$)$ & 0.87 (0.81 to 0.93 ) \\
\hline Hamilton et al, $2009^{28}$ & 27 (25.8 to 28.2 ) & 89 (89.1 to 89.7) & 2.55 (2.42 to 2.69$)$ & 0.82 (0.80 to 0.83 ) \\
\hline Panzuto et al, 2003'11 & 51 (35.1 to 67.1) & 53 (46.2 to 59.2 ) & $1.08(0.78$ to 1.50$)$ & 0.93 (0.66 to 1.30$)$ \\
\hline \multirow[t]{2}{*}{ Summary estimates } & 27 (25.9 to 28.2 ) & 89 (88.7 to 89.3 ) & 1.74 (1.11 to 2.72 ) & 0.84 (0.79 to 0.88 ) \\
\hline & $R=81.7 \%, P=0.004$ & $R=99.1 \%, P<0.001$ & $R=94.4 \%, P<0.001$ & $R=44.4 \%, P=0.17$ \\
\hline \multicolumn{5}{|l|}{ Anaemia } \\
\hline Hamilton $2008^{29}$ & 37 (35.7 to 39.1 ) & 92 (91.2 to 92.3) & 4.62 (3.03 to 7.06 ) & 0.68 (0.65 to 0.71$)$ \\
\hline Panzuto et al, 2003"11 & 68 (51.9 to 81.9) & 83 (77.5 to 87.4 ) & $3.98(2.81$ to 5.64$)$ & 0.38 (0.24 to 0.60$)$ \\
\hline \multicolumn{5}{|l|}{ Change in bowel habit } \\
\hline Hamilton et al, $2008^{28}$ & $11(10.4$ to 12.1$)$ & $99(98.9$ to 99.1$)$ & $11.47(10.12$ to 13.00$)$ & 0.90 (0.89 to 0.91$)$ \\
\hline Panzuto et al, 2003"1 & 20 (8.8 to 34.9) & 80 (73.8 to 84.4 ) & 0.95 (0.49 to 1.86$)$ & 1.01 (0.86 to 1.19$)$ \\
\hline \multicolumn{5}{|l|}{ Bloating } \\
\hline Panzuto et al, 2003"1 & 54 (38.7 to 67.9 ) & 39 (33.4 to 45.6 ) & 0.88 (0.63 to 1.15 ) & 1.18 (0.79 to 1.64$)$ \\
\hline
\end{tabular}

Rectal bleeding with abdominal pain. Six studies from five papers ${ }^{20,23-26}$ reported this symptom pair, ${ }^{19,21-24}$ with a total of 1466 evaluated participants. The pooled sensitivity was low, with no inconsistency between studies. Specificity was poor, with considerable inconsistency, indicating that these two symptoms occurring together are unlikely to be specific to colorectal cancer. The PLR and NLR were low INLR 1.04, 95\% $\mathrm{Cl}=0.82$ to 1.30), with moderate inconsistency. The PPV was $7.6 \%$, with greater inconsistency (Table 2 and Figure 2A). Rectal bleeding with weight loss. Six studies from five papers reported these symptoms, with a total of 1468 evaluated participants. 19,21-24 The pooled sensitivity of these symptoms was low but the specificity was stronger. The pooled PLR of 1.88 (95\% $\mathrm{Cl}=1.25$ to 2.83$)$ and NLR of $0.93(95 \% \mathrm{Cl}=$ 0.85 to 1.02 ) suggest that weight loss in addition to rectal bleeding increases the risk of an underlying cancer. There was little inconsistency between studies (Table 2 and Figure 2B).

Rectal bleeding with change in bowel habit. Seven studies from six papers reported this symptom, with a total of 1729 evaluated participants. 19,20-24 The pooled sensitivity and 
Figure 1. Positive predictive values of rectal bleeding in the diagnosis of colorectal cancer in primary care. Random effects pooled estimate (diamond) is based on a subgroup ( $B$ ) aged $\geq 50$ years.

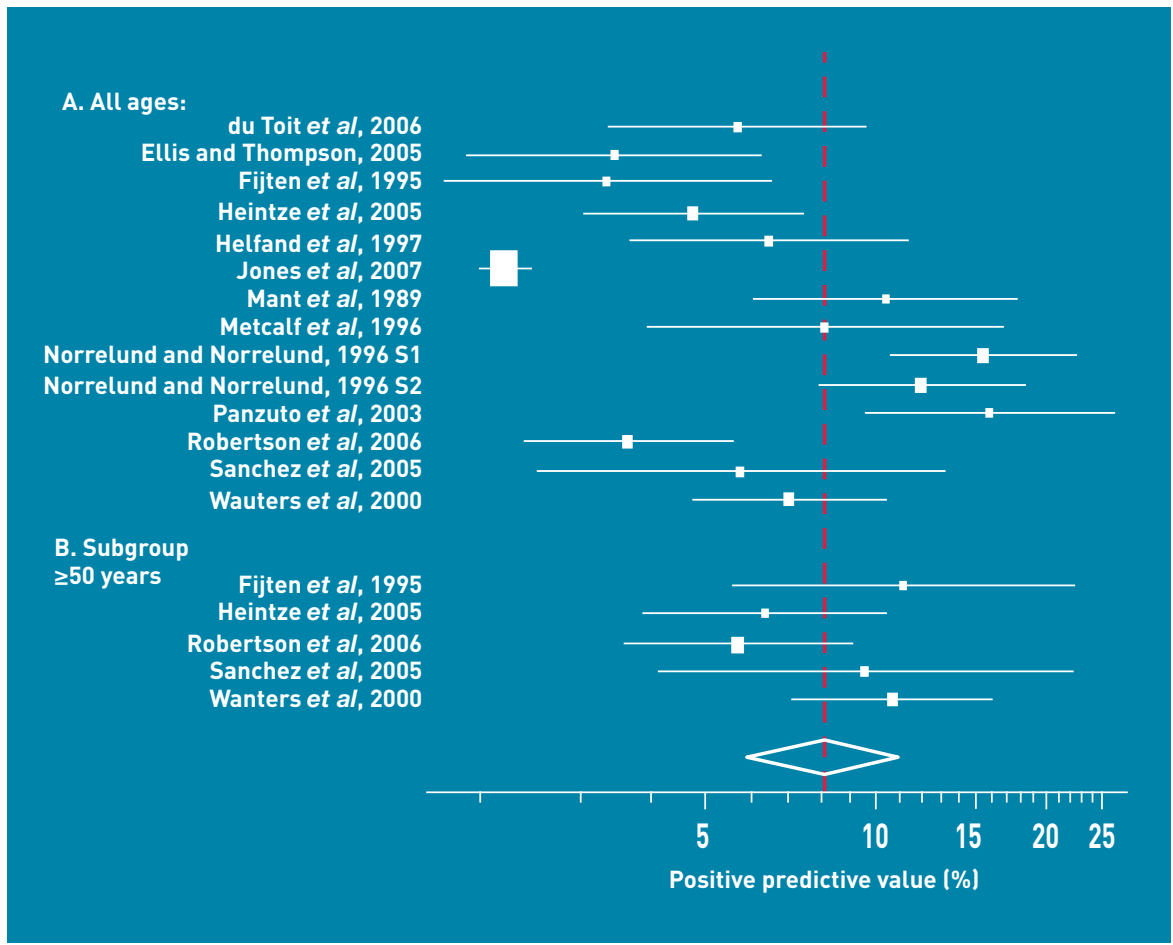

specificity of these symptoms was moderate, with substantial inconsistency between studies. The PLR of $1.81(95 \% \mathrm{Cl}=$ 1.33 to 2.46$)$ and NLR of $0.70(95 \% \mathrm{Cl}=0.51$ to 0.96 ) again suggest a change in bowel habit slightly increases the risk of cancer over and above that from rectal bleeding. (Table 2 and Figure 2C).

Rectal bleeding with anaemia. One study with 269 patients assessed this symptom pair. ${ }^{21}$ The sensitivity was comparable to that of rectal bleeding with abdominal pain, though the specificity was higher Consequently, the PLR and PPV were moderate although imprecise; the NLR was $0.70(95 \% \mathrm{Cl}=0.44$ to 1.11$)$ (Table 2)

Rectal bleeding with decreased appetite. The same study assessed this symptom pair. ${ }^{21}$ Sensitivity, specificity, and NLR (1.06; $195 \% \mathrm{Cl}=0.83$ to 1.34$)$ were low, with unremarkable PLR and PPV (Table 2).

Rectal bleeding with diarrhoea or constipation. A small study of 99 evaluated patients assessed these symptom pairs. ${ }^{23}$ The diagnostic performance of the symptom rectal bleeding with diarrhoea or constipation was imprecise for all findings
(Table 2). The NLR was unremarkable for diarrhoea $(1.03,95 \% \mathrm{Cl}=0.68$ to 1.57$)$, and low for constipation $(1.50,95 \% \mathrm{Cl}=1.10$ to 2.06).

Rectal bleeding with peri-anal symptoms. A single study of 266 patients evaluated this symptom pair using any peri-anal symptom. ${ }^{20}$ The sensitivity and specificity were poor. A NLR of $2.90(95 \% \mathrm{Cl}=1.75$ to 4.79 ) is evidence that the presence of perianal symptoms lessens the risk of colorectal cancer when the patient has rectal bleeding. A single study of 145 patients evaluated tenesmus specifically: all the findings were unremarkable $(N L R=$ 1.12. $95 \% \mathrm{Cl}=0.91$ to 1.37) (Table 2). ${ }^{22}$

\section{Abdominal pain}

Five studies examined this symptom. PPVs were calculated in three studies, 11,30,31 containing 1112 participants, giving an overall estimate of $3.3 \% 195 \% \mathrm{Cl}=0.7 \%$ to 15.6\%). However, considerable inconsistency estimated from another three studies of 46 164 participants, 11,27,28 had considerable inconsistency between studies $(R>89.0 \%$, $P \leq 0.001)$, possibly due to variations in study design and sample size (Table 1). was present (Table 3). The PLR and NLR 
Table 2. Sensitivity, specificity, positive likelihood ratio, and positive predictive value of symptom pairs

\begin{tabular}{|c|c|c|c|c|}
\hline Symptom pairs and study & $\begin{array}{l}\text { Sensitivity, } \\
\%(95 \% \mathrm{CI})\end{array}$ & $\begin{array}{l}\text { Specificity, } \\
\%(95 \% \mathrm{CI})\end{array}$ & $\begin{array}{l}\text { Positive likelihood } \\
\text { ratio, }(95 \% \mathrm{CI})\end{array}$ & $\begin{array}{l}\text { Positive predictive } \\
\text { value, } \%(95 \% \mathrm{CI})\end{array}$ \\
\hline \multicolumn{5}{|l|}{ Rectal bleeding with: } \\
\hline \multicolumn{5}{|l|}{ Abdominal pain } \\
\hline Mant et al, 198922 & 25 (7.3 to 52.4$)$ & $70(60.8$ to 77.4$)$ & $0.82(0.34$ to 1.99$)$ & 9.30 (2.59 to 22.1$)$ \\
\hline Metcalf et al, $1996^{23}$ & 38 (8.5 to 75.5$)$ & 57 (46.3 to 67.5 ) & $0.88(0.35$ to 2.21$)$ & $7.14(1.50$ to 19.5$)$ \\
\hline Norrelund and Norrelund, $1996,{ }^{19} \mathrm{~S} 1$ & 31 (16.1 to 50.0 ) & 78 (71.6 to 84.2 ) & $1.45(0.81$ to 2.60$)$ & 20.8 (10.5 to 35.0$)$ \\
\hline Robertson et al, $2006^{24}$ & 20 (5.7 to 43.7$)$ & $60(55.8$ to 64.0$)$ & $0.50(0.21$ to 1.21$)$ & $1.72(0.47$ to 4.36$)$ \\
\hline Summary estimates & $\begin{array}{l}33(24.0 \text { to } 42.5), \\
R=0.0 \%, P=0.42\end{array}$ & $\begin{array}{c}63(60.1 \text { to } 65.3) \\
R=91.3 \%, P<0.000\end{array}$ & $\begin{array}{l}1.03(0.63 \text { to } 1.69) \\
R=61.1 \%, P=0.025\end{array}$ & $\begin{array}{l}7.58(3.00 \text { to } 19.2) \\
R=83.8 \%, P<0.001\end{array}$ \\
\hline \multicolumn{5}{|l|}{ Weight loss } \\
\hline Fijten et al, $1995^{21}$ & 44 (13.7 to 78.8 ) & 85 (80.5 to 89.4 ) & $3.04(1.38$ to 6.68$)$ & $9.52(2.66$ to 22.6$)$ \\
\hline Mant et al, $1989^{22}$ & 13 (1.6 to 38.3$)$ & 91 (84.1 to 95.0) & $1.32(0.33$ to 5.38$)$ & 14.3 (1.78 to 42.8$)$ \\
\hline Metcalf et al, $1996^{23}$ & $25(3.2$ to 65.1$)$ & 86 (76.8 to 92.2) & 1.75 (0.48 to 6.43$)$ & $13.3(1.66$ to 40.5$)$ \\
\hline Norrelund and Norrelund, 1996, ${ }^{19} \mathrm{S1}$ & $16(5.3$ to 32.8$)$ & 90 (85.0 to 94.3 ) & 1.62 (0.64 to 4.07$)$ & $22.7(7.82$ to 45.4$)$ \\
\hline Robertson et al, $2006^{24}$ & $14(2.9$ to 34.9$)$ & 90 (86.9 to 92.0$)$ & 1.32 (0.45 to 3.88 ) & $4.84(1.01$ to 13.5$)$ \\
\hline Summary estimates & $\begin{array}{l}19(12.3 \text { to } 27.9), \\
R=0.0 \%, P=0.47\end{array}$ & $\begin{array}{l}89(86.7 \text { to } 90.2), \\
R=1.9 \%, P=0.40\end{array}$ & $\begin{array}{l}1.88(1.25 \text { to } 2.83), \\
R=0.0 \%, P=0.80\end{array}$ & $\begin{array}{l}13.4(8.15 \text { to } 21.9) \\
R=9.9 \%, P=0.35\end{array}$ \\
\hline \multicolumn{5}{|l|}{ Change in bowel habit } \\
\hline Ellis and Thompson, $2005^{20}$ & 100 (71.7 to 100.0$)$ & 58 (51.3 to 63.8) & 2.26 (1.88 to 2.72$)$ & 9.24 (4.7 to 15.9 ) \\
\hline Fijten et al, $1995^{21}$ & 78 (40.0 to 97.2) & 73 (66.8 to 78.0$)$ & $2.85(1.91$ to 4.26$)$ & $8.97(3.7$ to 17.6$)$ \\
\hline Mant et al, 198922 & $38(15.2$ to 64.6$)$ & 61 (51.6 to 69.2) & $0.95(0.49$ to 1.86$)$ & $10.7(4.04$ to 21.9$)$ \\
\hline Metcalf et al, $1996^{23}$ & 50 (15.7 to 84.3) & $62(50.8$ to 71.6$)$ & 1.30 (0.62 to 2.72$)$ & 10.3 (2.87 to 24.2 ) \\
\hline Norrelund and Norrelund, 1996, ${ }^{19} \mathrm{~S} 1$ & 59 (40.6 to 76.3 ) & 77 (69.8 to 82.7 ) & 2.55 (1.72 to 3.77$)$ & $31.7(20.6$ to 45.0$)$ \\
\hline Norrelund and Norrelund, 1996, ${ }^{19}$ S2 & 46 (24.4 to 67.8$)$ & 72 (63.2 to 79.1 ) & 1.60 (0.94 to 2.73$)$ & 20.8 (10.5 to 35.0$)$ \\
\hline Robertson et al, $2006^{24}$ & 59 (36.4 to 79.3 ) & 55 (50.6 to 58.9) & 1.31 (0.91 to 1.87$)$ & 4.83 (2.6 to 8.12 ) \\
\hline Summary estimates & $\begin{array}{c}58(49.0 \text { to } 67.3) \\
R=66.5 \%, P=0.006\end{array}$ & $\begin{array}{c}63(60.4 \text { to } 65.1) \\
R=88.0 \%, P<0.001\end{array}$ & $\begin{array}{l}1.81(1.33 \text { to } 2.46) \\
R=74.6 \%, P=0.001\end{array}$ & $\begin{array}{l}11.8 \text { (6.78 to } 20.4), \\
R=77.1 \%, P<0.001\end{array}$ \\
\hline \multicolumn{5}{|l|}{ Anaemia } \\
\hline Fijten et al, $1995^{21}$ & $33(7.5$ to 70.1$)$ & 96 (92.6 to 97.9 ) & 7.88 (2.65 to 23.4$)$ & $21.4(4.70$ to 50.8$)$ \\
\hline \multicolumn{5}{|l|}{ Diarrhoea } \\
\hline Metcalf et al, $1996^{23}$ & $25(3.20$ to 65.1$)$ & 73 (62.2 to 81.4$)$ & $0.91(0.26$ to 3.16$)$ & 7.4 (0.91 to 24.3$)$ \\
\hline \multicolumn{5}{|l|}{ Constipation } \\
\hline Metcalf et al, $1996^{23}$ & $13(0.30$ to 52.7$)$ & 58 (47.4 to 68.5 ) & 0.30 (0.05 to 1.90$)$ & $2.6(0.07$ to 13.5$)$ \\
\hline \multicolumn{5}{|l|}{ Peri-anal symptoms } \\
\hline Ellis and Thompson, $2005^{20}$ & 36 (10.9 to 69.2) & $22(17.0$ to 27.5$)$ & $0.47(0.21$ to 1.02$)$ & $2.0(0.54$ to 4.80$)$ \\
\hline \multicolumn{5}{|l|}{ Tenesmus } \\
\hline Mant et al, $1989^{22}$ & $13(1.6$ to 38.3$)$ & 78 (70.2 to 85.1$)$ & 0.58 (0.15 to 2.19$)$ & $6.7(0.82$ to 22.1$)$ \\
\hline
\end{tabular}

\section{Anaemia}

Five studies, with a total of 14625 participants, examined this feature. PPVs were calculated in four studies of 928 participants. ${ }^{11,13,32,33}$ The large degree of inconsistency in the pooled PPV may be due to a large proportion of true positives in the study by Panzuto et al. ${ }^{11}$ When this study was excluded, the pooled PPV reduced to $7.0 \%(95 \% \mathrm{Cl}=4.2$ to 11.4$)$ with lower inconsistency ( $R=40 \%, P=0.19)$ (Table 3).

In a large case-control study, ${ }^{29}$ the sensitivity of anaemia for colorectal cancer was similar in males and females over the age of 30 years $137.2 \%$ versus $37.6 \% ; \chi^{2} P=$ 0.82). A smaller cohort study reported a higher sensitivity for anaemia. ${ }^{11}$ The PLRs of the two studies were similar in magnitude (Table 1).

\section{Weight loss, diarrhoea, and constipation}

Three studies of 46164 participants, examined the association of weight loss, diarrhoea, and constipation separately (Table 1). ${ }^{11,27,28}$ Inconsistency was considerable for all parameters $(R>81 \%, P \leq 0.004)$ with the 
Figure 2. Positive likelihood ratios (LRs) of rectal bleeding and another symptom: $A$, abdominal pain; $B$ weight loss; $C$, change in bowel habit.

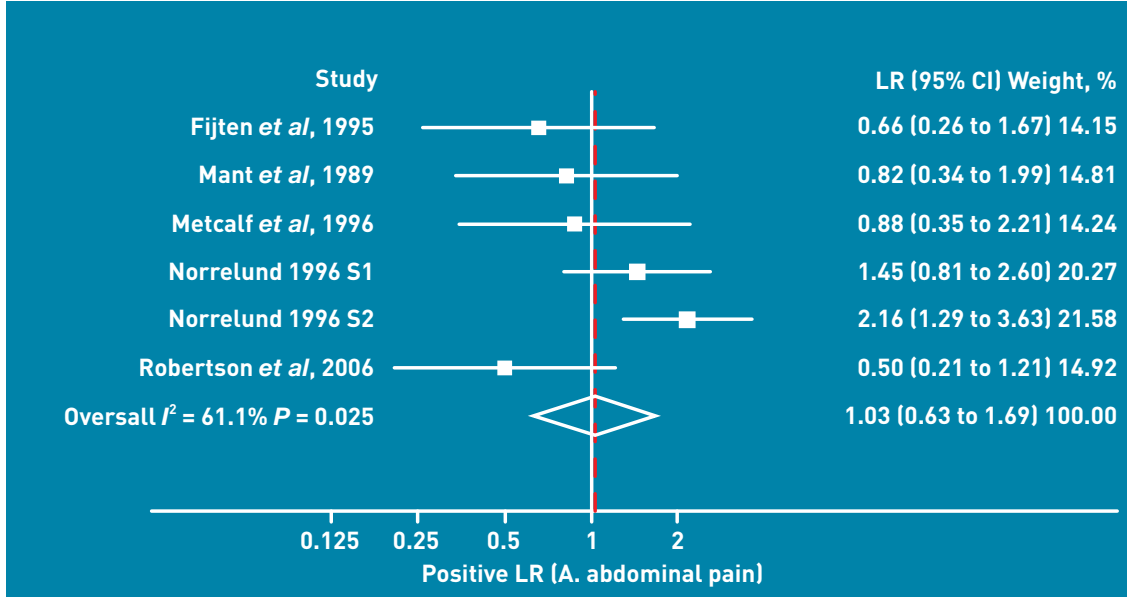

Study

Fijten et al, 1995

Mant et al, 1989

Metcalf et al, 1996

Norrelund $1996 \mathrm{S1}$

Norrelund 1996 S2

Robertson et al, 2006

Oversall $I^{2}=0.0 \% P=0.797$

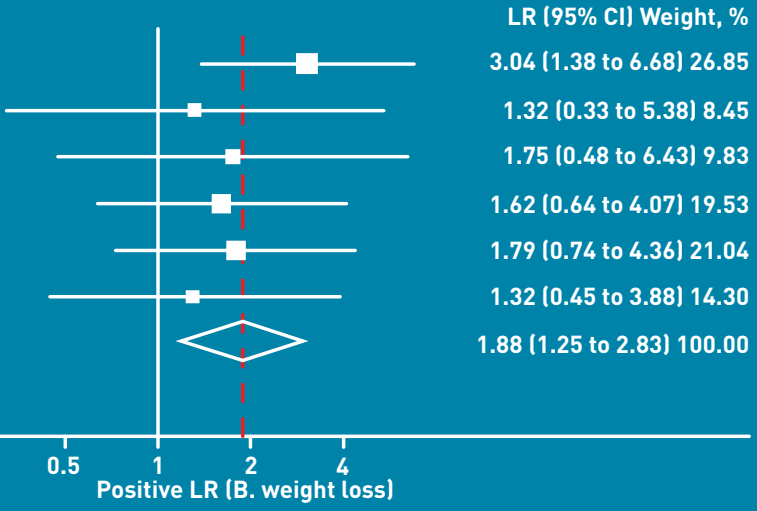

Study

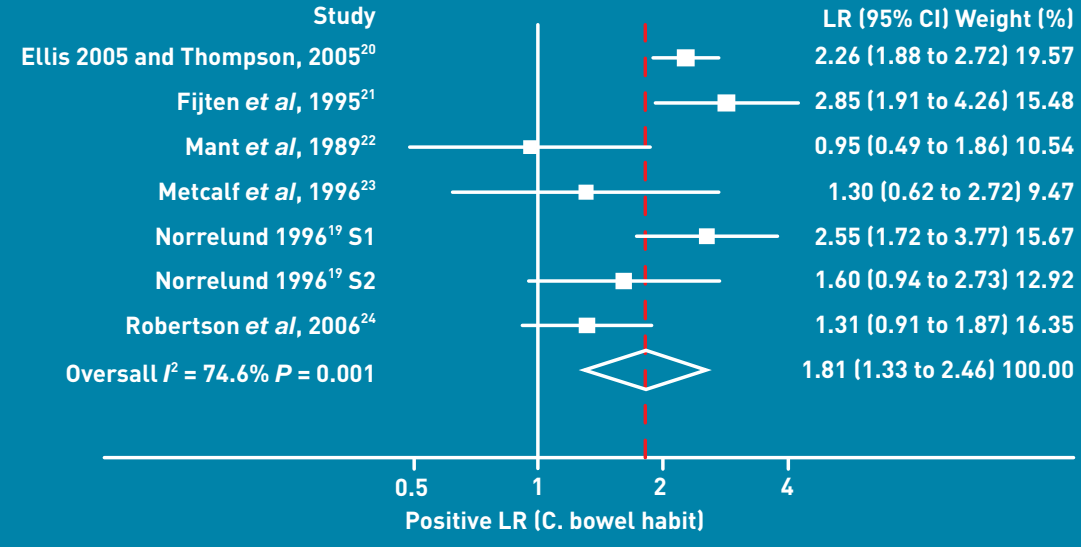

exception of the NLR for constipation $(R=$ $44 \%, P=0.17)$. PPVs in the study by Panzuto et al were variable (Table 3). ${ }^{11}$

\section{Change in bowel habit}

Two studies of 44071 participants evaluated this symptom. ${ }^{11,28}$ The PLRs were significantly different $(P<0.001)$, while the NLRs were more consistent $(P=0.15)$, indicating that patients without these symptoms could not have cancer ruled out (Table 1). The PPV in the study by Panzuto et al was similar to that of constipation and diarrhoea (Table 3). ${ }^{11}$ 


\begin{tabular}{|c|c|c|}
\hline Symptom & Study & PPV, $\%(95 \%$ CI) \\
\hline \multirow[t]{3}{*}{ Abdominal pain } & Bellentani et al, $1990^{30}$ & 3.94 (1.90 to 7.12 ) \\
\hline & Muris et al, $1993^{31}$ & 0.52 (0.11 to 1.51 ) \\
\hline & Panzuto et al, $2003^{11}$ & 13.5 (9.26 to 18.7 ) \\
\hline \multirow[t]{2}{*}{ Summary estimate } & & 3.29 (0.69 to 15.6$)$, \\
\hline & & $\begin{array}{c}P=94.1 \% \\
P<0.001\end{array}$ \\
\hline \multirow[t]{4}{*}{ Anaemia } & Farrus et al, 2000 ${ }^{13}$ & 2.30 (0.28 to 8.06$)$ \\
\hline & Lucas et al, $1996^{32}$ & 6.92 (3.21 to 12.7 ) \\
\hline & Panzuto et al, 2003"11 & $40.6(28.9$ to 53.1$)$ \\
\hline & Yates et al, $2004^{33}$ & 8.59 (6.12 to 11.6$)$ \\
\hline \multirow[t]{3}{*}{ Summary estimate } & & 9.70 (3.52 to 26.8), \\
\hline & & $R=91.7 \%$ \\
\hline & & $P<0.001$ \\
\hline Weight loss & Panzuto et al, 2003'11 & 35.7 (9.3 to 18.6$)$ \\
\hline Change in bowel habit & Panzuto et al, 2003"11 & 14.0 (6.26 to 25.8 ) \\
\hline Diarrhoea & Panzuto et al, 2003 & 11.8 (5.8 to 20.6 ) \\
\hline Constipation & Panzuto et al, 2003"11 & 15.7 (10.0 to 23.0$)$ \\
\hline Bloating & Panzuto et al, $2003^{11}$ & 13.2 (8.44 to 19.3 ) \\
\hline
\end{tabular}

\section{Bloating}

One study of 280 participants' evaluated bloating. ${ }^{11}$ The study was small and the GPs had recently taken a training programme on colorectal diseases (Tables 1 and 3). This may have influenced referral behaviour.

\section{Any symptom}

Two studies, with 965 participants, grouped relevant presenting symptoms to evaluate the association with a diagnosis of colorectal cancer or other conditions. ${ }^{15,16}$ As this is not as useful to clinicians as specific symptoms, these have not been reported further here.

\section{Subgroup analyses}

Subgroup analyses of PPVs for rectal bleeding were conducted in single-centre versus multicentre studies; symptom data collection by template or questionnaire versus by consultation or not reported; firstonset only rectal bleeding versus any onset, including those with a proportion of firstonset bleeding; and in studies where QUADAS scores were low. Three other subgroup analyses /prospective versus retrospective designs; number of cancers detected $<100$ versus $\geq 100$; and study size $<1000$ versus $\geq 1000$ ) were not performed because of the small number of large

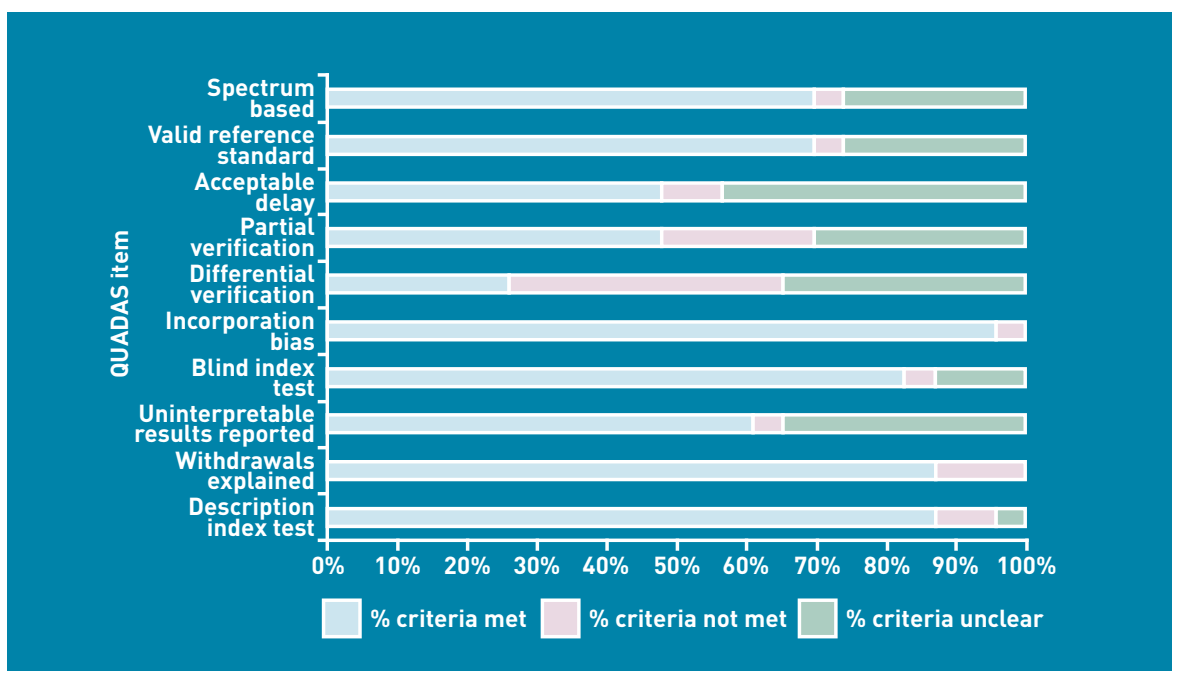


studies, or retrospective or case-control designs. No significant differences were found between the subgroups that could be analysed. No significant differences were found between studies in the PPV of rectal bleeding (criterion met versus not met or unclearl for the lowest-scoring QUADAS items' differential verification bias and partial verification bias.

\section{Quality assessment}

The quality assessment of 23 studies is shown in Figure 3. The criteria 'met' for differential and partial verification bias were relatively low (26\% and $48 \%$ respectively) because of the range of reference tests reported; and not all participants received a reference standard. This is not unusual at the interface of primary and secondary care. Acceptable delay was met in $48 \%$ of studies, though a large proportion (43\%) did not report this item.

\section{DISCUSSION}

\section{Summary}

This review has confirmed the association between colorectal cancer and its main symptoms when reported to primary care. It was possible to quantify the associations by calculating summary PLRs and PPVs. The summary PLR for unpaired symptoms ranged from 5.3 for rectal bleeding to 1.7 for constipation. Intermediate values were found for weight loss, abdominal pain, and diarrhoea. There were not enough studies to perform a meta-analysis for the single symptoms of anaemia, change in bowel habit, and bloating, although the two studies of anaemia found a small increase in the likelihood of cancer. When rectal bleeding was accompanied by a second symptom the risk of colorectal cancer was greatest when weight loss or a change in bowel habit was also present.

\section{Strengths and limitations}

The study methods followed the traditional schema for systematic reviews. A broad selection of symptoms was chosen to ensure relevant studies were identified. All selected studies were observational, and most were multicentre. They were largely from Europe, which is to be expected. Studies performed reasonably well against the QUADAS criteria, which are designed for use with diagnostic tests. The lack of gold-standard confirmation (histology) of colorectal cancer diagnosis is a small concern, although it is reasonable to assume patients will have been given such a major diagnosis with good clinical reason, and most were followed up clinically. In this review, the larger studies all originated from electronic databases, so were reliant on accurate recording of symptoms. It is possible their results are not directly comparable to smaller studies.

There are several potential limitations. There was considerable heterogeneity between studies. Furthermore, the strength of the association between unpaired symptoms and cancer was often based on relatively few studies. Also, other symptoms may actually have been present but were not reported. Some studies used questionnaires to record specific patient symptoms. This may increase symptom reporting. Heterogeneity may also be due to uncontrollable factors such as variations in referral rates and differing severity of symptoms. It was possible to calculate negative predictive values, but these have been omitted from this paper, as they are not powerful enough on a 'rule-out' basis - it is impossible to state confidently that the absence of a particular symptom means cancer is not present. Other limitations include the generally small study sizes, as shown by wide $\mathrm{Cls}$. The use of a search filter for primary health care reduced the number of candidate studies. Eleven studies were identified from reference lists, but only one was included, suggesting that the filter was not overly restrictive.

The decision to restrict this review to primary care studies is a strength, as one key clinical decision is whether to refer from primary care to secondary care for investigation of possible cancer. This cannot be done using secondary care data, as the predictive values are generally much higher than in the primary care population Ireflecting the selection process that has taken place before referral). In this respect, this review differs from previous reviews $s^{4,5}$, - and the difference matters. ${ }^{34}$ Investigation of colorectal cancer costs more than treatment, at an estimated £290 million annually, most of which relates to investigation of people who transpire not to have cancer. ${ }^{35}$ Any improvement in selection of patients for investigation would yield financial as well 
as clinical benefits, although countries with lower-cost investigations would see fewer of these.

\section{Comparison with existing literature}

The symptom that has been studied most is rectal bleeding. As the incidence of colorectal cancer is very low below the age of 50 years, the pooled estimate of PPV was restricted to those aged $\geq 50$ years. This was also as near as the data would allow to the age cut-off for rectal bleeding in National Institute for Health and Clinical Excellence (NICE) guidance of 40 years. The pooled estimate of $8.1 \%$ is higher than expected. If this figure were taken at face value, it would be easy to recommend investigation of all rectal bleeding, whether accompanied by other symptoms or not. Some caution must be exercised, as subgroup analyses may be more biased; in particular, some studies only included patients in whom rectal bleeding was the focus of the consultation. This may overestimate the PPV. It is reasonable to expect a symptom that the patient deems important enough to make the focus of the consultation to be of higher risk. Similarly, the subgroup analysis of new-onset rectal bleeding versus all rectal bleeding yielded negative results. This counterintuitive finding may be true, or may simply reflect the small number of studies in this analysis.

Some symptoms lweight loss and change in bowel habit) increased the risk of bowel cancer when accompanying rectal bleeding, compared to rectal bleeding alone - as shown by a PLR of nearly 2.0 . Conversely, other symptoms /decreased appetite, diarrhoea, constipation, and perianal symptoms) appeared to lower the risk of colorectal cancer when accompanying rectal bleeding, with a PLR $\leq 1.0$. In the first version of national referral guidance to UK GPs, peri-anal symptoms were considered to obviate the need for referral in a patient with rectal bleeding. ${ }^{36}$ This advice was removed in the 2005 version, ${ }^{3}$ but is supported by the present findings. Irondeficiency anaemia has long been recognised as a marker of colorectal cancer. Furthermore, it is the symptom associated with the longest delays in diagnosis and the worst prognosis. ${ }^{37}$ The pooled PPV was $9.7 \%$ lor $7.0 \%$ if the study of Panzuto et al" study is removed). Such a figure clearly warrants investigation. Only one study was large enough to examine different levels of anaemia, ${ }^{29}$ so it is difficult to extrapolate from these findings a specific threshold of haemoglobin that warrants investigation.

\section{Implications for practice}

Overall, the findings of this study largely support referral guidance, including that for the UK. At the time these guidelines were formulated, there was relatively little primary care research to underpin the recommendations. No specific threshold level of risk was cited in NICE guidance, but it seems reasonable to suppose that most patients would elect for a figure of around $1-2 \%{ }^{38} \mathrm{~A}$ review of all primary cancer PPVs above $5 \%$ was published in the British Journal of General Practice while this paper was under submission, reporting such a high PPV only in iron-deficiency anaemia and for rectal bleeding, but only for some groups of patients with these symptoms, largely those who were older. ${ }^{39}$ Clearly, such a high level of risk warrants investigation, but for lower risks the review presented here should help to define symptoms (or symptom complexes) that are worthy of rapid investigation. Access to cancer investigations is likely to be increased in the UK; for colorectal cancer we are now better placed to decide which symptoms should qualify.

The deliberate restriction of this review to studies containing primary care data means that the results differ from previous systematic reviews using data from both primary care and secondary care. 4,5 The predictive value of tests lor in this case, symptoms) is dependent on the prior probability of the disease of interest in the population. The selection process undertaken by primary care means that patients seen in secondary care have a much higher prior probability of cancer. This is not semantics: by restricting this review to the primary care population, the results can guide primary care physicians in their referral decisions. Indeed, one can advance this argument: if a patient has a symptom of possible bowel cancer, they may benefit from colonoscopy even if no cancer is found - it is still worth diagnosing, for example, ulcerative colitis. Thus, the PPV for any disease worth identifying' will be higher than the values calculated for cancer alone. 


\section{REFERENCES}

1. Goodyear S, Stallard N, Gaunt A, et al. Local impact of the English arm of the UK Bowel Cancer Screening Pilot study. Br J Surg 2008; 95(9): 1172-1179.

2. Hamilton W, Sharp D. Diagnosis of colorectal cancer in primary care: the evidence base for guidelines. Fam Pract 2004; 21(1): 99-106.

3. National Institute for Health and Clinical Excellence. Referral guidelines for suspected cancer. London: NICE, 2005.

4. Ford AC, Veldhuyzen van Zanten SJ, et al. Diagnostic utility of alarm features for colorectal cancer: systematic review and meta analysis. Gut 2008; 57(11): 1545-1553.

5. Jellema P, van der Windt DAWM, Bruinvels DJ, et al. Value of symptoms and additional diagnostic tests for colorectal cancer in primary care: systematic review and meta-analysis. BMJ 2010; 340(313): c1269.

6. Okkes I, Jamoulle M, Lamberts H, Bentzen N. ICPC-2-E: the electronic version of ICPC-2. Differences from the printed version and the consequences. Fam Pract 2000; 17(2): 101-107.

7. Whiting P, Rutjes A, Reitsma J, et al. The development of QUADAS: a tool for the quality assessment of studies of diagnostic accuracy included in systematic reviews. BMC Med Res Meth 2003; 3: 25.

8. Zamora J, Abraira V, Muriel A, et al. Meta-DiSc: a software for meta-analysis of test accuracy data. BMC Med Res Meth 2006; 6: 31.

9. Deeks JJ. Systematic reviews in health care: systematic reviews of evaluations of diagnostic and screening tests. BMJ 2001; 323(7305): 157-162.

10. Lijmer JG, Mol, BW, Heisterkamp S, et al. Empirical evidence of design-related bias in studies of diagnostic tests. JAMA 1999; 282(11): 1061-1066.

11. Panzuto F, Chiriatti A, Bevilacqua S, et al. Symptom-based approach to colorectal cancer: survey of primary care physicians in Italy. Dig Liver Dis 2003; 35(12): $869-875$

12. Du Toit J, Hamilton W, Barraclough K. Risk in primary care of colorectal cancer from new onset rectal bleeding: 10 year prospective study. BMJ 2006; 333(7558): 69-70.

13. Farrus PM, Perez OA, Mayer Pujadas MA, et al. Anaemia in primary care: etiology and morphological characteristics. Aten Primaria 2000; 25(4): 230-235.

14. Helfand M, Marton KI, Zimmer-Gembeck MJ, Sox HC Jr. History of visible rectal bleeding in a primary care population. Initial assessment and 10-year follow-up. JAMA 1997; 277(1): 44-48.

15. Carlsson L, Hakansson A, Nordenskjold B. Common cancer-related symptoms among GP patients. Opportunistic screening in primary health care. Scand J Prim Health Care 2001; 19(3): 199-203.

16. Muris JW, Starmans R, Fijten GH, et al. Non-acute abdominal complaints in general practice: diagnostic value of signs and symptoms. Br J Gen Pract 1995; 45(395): 313-316.

17. Heintze C, Matysiak-Klose D, Krohn T, et al. Diagnostic work-up of rectal bleeding in general practice. Br J Gen Pract 2005; 55(510): 14-19.

18. Jones R, Latinovic R, Charlton J, Gulliford MC. Alarm symptoms in early diagnosis of cancer in primary care: cohort study using General Practice Research Database. BMJ 2007; 334(7602): 1040

19. Norrelund $\mathrm{N}$, Norrelund $\mathrm{H}$. Colorectal cancer and polyps in patients aged 40 years and over who consult a GP with rectal bleeding. Fam Pract 1996; 13(2): 160-165.

20. Ellis BG, Thompson MR. Factors identifying higher risk rectal bleeding in general practice. Br J Gen Pract 2005; 55(521): 949-955.

21. Fijten GH, Starmans R, Muris JW, et al. Predictive value of signs and symptoms for colorectal cancer in patients with rectal bleeding in general practice. Fam Pract 1995; 12(3): 279-286.

22. Mant A, Bokey EL, Chapuis PH, et al. Rectal bleeding. Do other symptoms aid in diagnosis? Dis Colon Rectum 1989; 32(3): 191-196.

23. Metcalf JV, Smith J, Jones R, Record CO. Incidence and causes of rectal bleeding in general practice as detected by colonoscopy. Br J Gen Pract 1996; 46(404): 161-164.

24. Robertson R, Campbell C, Weller DP, et al. Predicting colorectal cancer risk in patients with rectal bleeding. Br J Gen Pract 2006; 56(531): 763-767.

25. Sanchez A, Munoz C, Bujanda L, et al. The value of colonoscopy to assess rectal bleeding in patients referred from Primary Care Units. Rev Esp Enferm Dig 2005; 97(12): 870-876.

26. Wauters H, Van Casteren V, Buntinx F. Rectal bleeding and colorectal cancer in general practice: diagnostic study. BMJ 2000; 321(7267): 998-999.

27. Hamilton W, Round A, Sharp D, Peters TJ. Clinical features of colorectal cancer before diagnosis: a population-based case-control study. Br J Cancer 2005; 93(4): 399-405.

28. Hamilton W, Lancashire R, Sharp D, et al. The risk of colorectal cancer with symptoms at different ages and between the sexes: a case-control study. BMC Med 2009; 7: 17.

29. Hamilton W, Lancashire R, Sharp D, et al. The importance of anaemia in diagnosing colorectal cancer: a case-control study using electronic primary care records. Br J Cancer 2008; 98(2): 323-327.

30. Bellentani S, Baldoni P, Petrella S, et al. A simple score for the identification of patients at high risk of organic diseases of the colon in the family doctor consulting room. The Local IBS Study Group. Fam Pract 1990; 7(4): 307-312.

31. Muris JW, Starmans R, Fijten GH, et al. Abdominal pain in general practice. Fam Pract 1993; 10(4): 387-390.

32. Lucas CA, Logan EC, Logan RF. Audit of the investigation and outcome of irondeficiency anaemia in one health district. J R Coll Physicians Lond 1996; 30(1): 33-36.

33. Yates JM, Logan ECM, Stewart RM. Iron deficiency anaemia in general practice: clinical outcomes over three years and factors influencing diagnostic investigations. Postgrad Med J 2004; 80(945): 405-410.

34. Rubin G, Hamilton W. Alarm features of colorectal cancer. Gut 2009; 58(7): 1026

35. York Health Economics Consortium. Bowel cancer services: costs and benefits. London: Department of Health, 2007. http://php.york.ac.uk/inst/yhec/?q=projects/report/costs-and-benefits-bowelcancer-services-england-final-report laccessed 11 Mar 2011).

36. National Institute for Health and Clinical Excellence. Referral guidelines for suspected cancer. London: National Institute for Health and Clinical Excellence, 2000

37. Stapley S, Peters TJ, Sharp D, Hamilton W. The mortality of colorectal cancer in relation to the initial symptom at presentation to primary care and to the duration of symptoms: a cohort study using medical records. Br J Cancer 2006; 95(10): 1321-1325

38. Barraclough $\mathrm{K}$. The predictive value of cancer symptoms in primary care. $\mathrm{Br} \mathrm{J}$ Gen Pract 2010; 60(578): 639-640

39. Shapley M, Mansell G, Jordan JL, Jordan KP. Positive predictive values of $\geq 5 \%$ in primary care for cancer: systematic review. Br J Gen Pract 2010; 60(578): 366-377. 


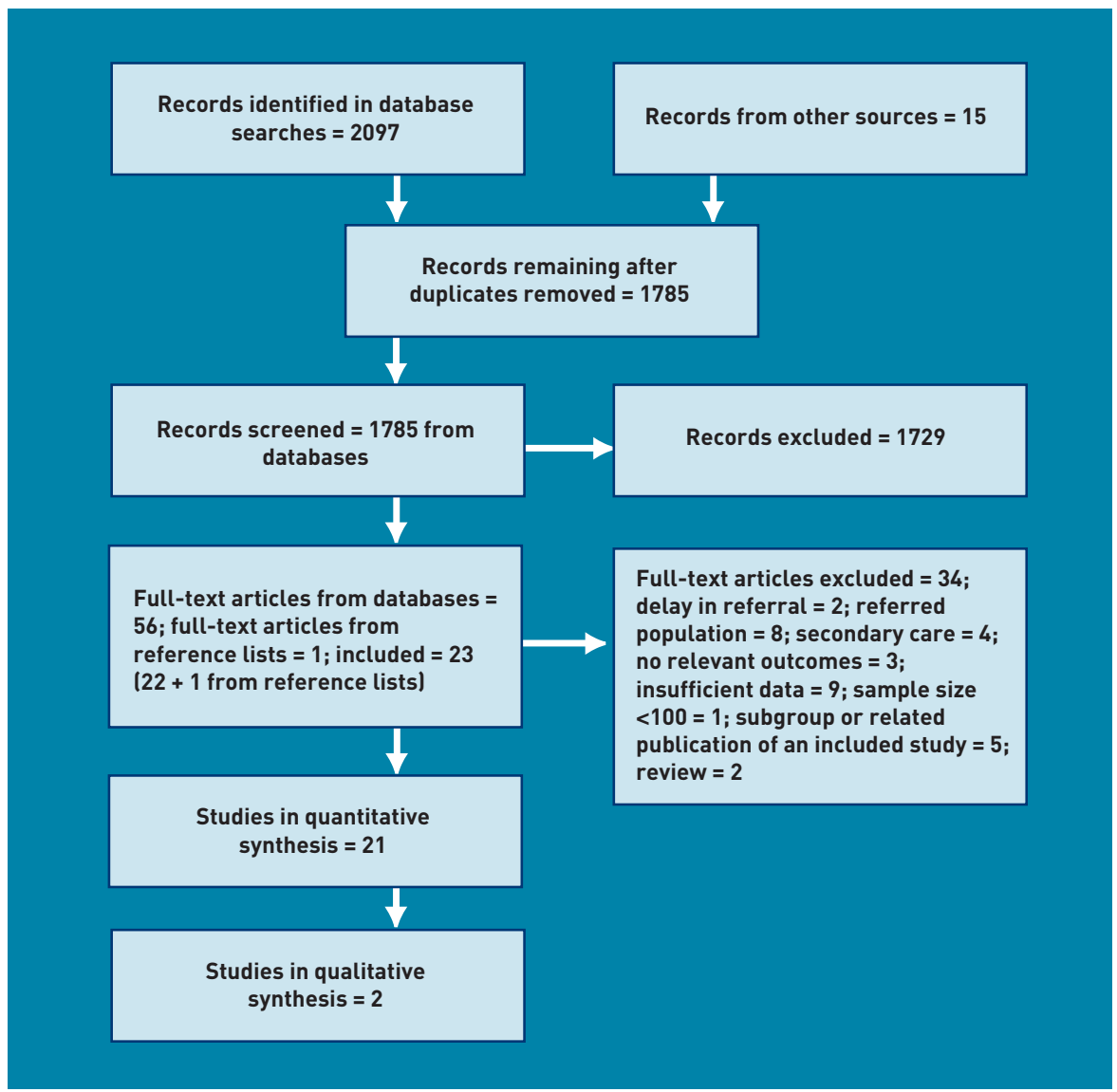




\section{Appendix 2. Characteristics of included studies}

\begin{tabular}{|c|c|c|c|c|c|c|}
\hline Study & Country & Design & $\begin{array}{l}\text { Number } \\
\text { recruited }\end{array}$ & $\begin{array}{l}\text { Number } \\
\text { eligible }\end{array}$ & $\begin{array}{l}\text { Patients with } \\
\text { colorectal cancer, } n \text { (\%) }\end{array}$ & Reference standard \\
\hline $\begin{array}{l}\text { Bellentani et al, } \\
1990^{30}\end{array}$ & Italy & $\begin{array}{l}\text { Prospective } \\
\text { consecutive }\end{array}$ & 254 & 254 & $10(3.9)$ & $\begin{array}{l}\text { Colonoscopy or double-contrast barium enema, } \\
\text { follow-up at } 2 \text { months }\end{array}$ \\
\hline $\begin{array}{l}\text { Carlsson et al, } \\
2001^{15}\end{array}$ & Sweden & $\begin{array}{l}\text { Prospective } \\
\text { cohort }\end{array}$ & 379 & 28 & 5 (17.8) & Not reported; several cancers examined \\
\hline $\begin{array}{l}\text { du Toit et al, } \\
2006^{12}\end{array}$ & UK & $\begin{array}{l}\text { Prospective } \\
\text { cohort }\end{array}$ & 265 & 265 & $15(5.7)$ & $\begin{array}{l}\text { Colonoscopy, flexible sigmoidoscopy or rigid } \\
\text { sigmoidoscopy with barium enema }\end{array}$ \\
\hline \multicolumn{2}{|c|}{$\begin{array}{l}\text { Ellis and Thompson, UK } \\
2005^{20}\end{array}$} & $\begin{array}{l}\text { Prospective } \\
\text { cohort }\end{array}$ & 319 & 319 & $11(3.4)$ & $\begin{array}{l}\text { Colonoscopy, flexible sigmoidoscopy, barium enema } \\
\text { and } 18 \text { months' follow-up }\end{array}$ \\
\hline $\begin{array}{l}\text { Farrus et al, } \\
2000^{13}\end{array}$ & Spain & $\begin{array}{l}\text { Prospective } \\
\text { cohort }\end{array}$ & 112 & 87 & $2(2.3)$ & Colonoscopy \\
\hline $\begin{array}{l}\text { Fijten et al, } \\
1995^{21}\end{array}$ & Netherlands & $\begin{array}{l}\text { Prospective } \\
\text { consecutive }\end{array}$ & 269 & 269 & 9 (3.3) & $\begin{array}{l}\text { Colonoscopy, sigmoidoscopy, X-ray, ultrasonography, } \\
\text { follow-up 15-25 months }\end{array}$ \\
\hline $\begin{array}{l}\text { Hamilton et al, } \\
2005^{27}\end{array}$ & UK & $\begin{array}{c}\text { Matched } \\
\text { case-control }\end{array}$ & 2093 & 2093 & $349(16.7)$ & Histology or strong clinical evidence \\
\hline $\begin{array}{l}\text { Hamilton et al, } \\
2008^{29}\end{array}$ & UK & $\begin{array}{c}\text { Matched } \\
\text { case-control }\end{array}$ & 13697 & 13697 & $3183(23.2)$ & Not reported in THIN ${ }^{b}$ database \\
\hline $\begin{array}{l}\text { Hamilton et al, } \\
2009^{28}\end{array}$ & UK & $\begin{array}{c}\text { Matched } \\
\text { case-control }\end{array}$ & 43791 & 43791 & $5477(12.5)$ & Not reported in THIN database \\
\hline $\begin{array}{l}\text { Heintze et al, } \\
2005^{17}\end{array}$ & Germany & $\begin{array}{l}\text { Prospective } \\
\text { cohort }\end{array}$ & 422 & 422 & $\begin{array}{l}17(4.0) ; \\
3 \text { in situ }\end{array}$ & Colonoscopy, sigmoidoscopy, ultrasonography \\
\hline $\begin{array}{l}\text { Helfand et al, } \\
1997^{14}\end{array}$ & USA & $\begin{array}{l}\text { Prospective } \\
\text { cohort }\end{array}$ & 297 & 201 & 13 (6.5) & $\begin{array}{l}\text { Rigid sigmoidoscopy with biopsy, and } \\
\text { double-contrast barium enema, follow-up } 6 \text { and } \\
12 \text { months }\end{array}$ \\
\hline $\begin{array}{l}\text { Jones et al, } \\
2007^{18}\end{array}$ & UK & $\begin{array}{l}\text { Retrospective } \\
\text { cohort }\end{array}$ & 15314 & 15289 & $338(2.2)$ & Not reported \\
\hline $\begin{array}{l}\text { Lucas et al, } \\
1996^{32}\end{array}$ & UK & $\begin{array}{c}\text { Retrospective } \\
\text { cohort }\end{array}$ & 130 & 130 & 9 (6.9) & $\begin{array}{l}\text { Colonoscopy, sigmoidoscopy, biopsy, barium enema, } \\
\text { follow-up } 2 \text { years }\end{array}$ \\
\hline $\begin{array}{l}\text { Mant et al, } \\
198922\end{array}$ & Australia & $\begin{array}{l}\text { Prospective } \\
\text { cohort }\end{array}$ & 248 & 145 & $15(10.3)$ & Histology, colonoscopy, follow-up 15-25 months \\
\hline $\begin{array}{l}\text { Metcalf et al, } \\
1996^{23}\end{array}$ & UK & $\begin{array}{l}\text { Prospective } \\
\text { cohort }\end{array}$ & 119 & 99 & $8(8.1)$ & Histology, colonoscopy \\
\hline $\begin{array}{l}\text { Muris et al, } \\
1993^{31}\end{array}$ & Netherlands & $\begin{array}{l}\text { Prospective } \\
\text { consecutive }\end{array}$ & 578 & 578 & $3(0.5)$ & $\begin{array}{l}\text { Colonoscopy, sigmoidoscopy, X-ray, ultrasonography, } \\
\text { follow-up } 15 \text { months }\end{array}$ \\
\hline $\begin{array}{l}\text { Muris et al, } \\
1995^{16}\end{array}$ & Netherlands & $\begin{array}{l}\text { Prospective } \\
\text { cohort }\end{array}$ & 933 & 933 & $4(0.4)$ & $\begin{array}{l}\text { Endoscopy, other confirmatory tests not reported, } \\
\text { follow-up at least } 1 \text { year }\end{array}$ \\
\hline $\begin{array}{l}\text { Norrelund and } \\
\text { Norrelund, } 1996\end{array}$ & $\begin{array}{l}\text { Denmark } \\
6^{19}\end{array}$ & $\begin{array}{l}\text { Prospective } \\
\text { consecutive }\end{array}$ & $\begin{array}{l}\text { S1 208; } \\
\text { S2 209 }\end{array}$ & $208 ; 209$ & $\begin{array}{l}32(15.4) ; \\
25(12.0)\end{array}$ & $\begin{array}{l}\text { Histology, colonoscopy, barium enema, annual } \\
\text { follow-up }\end{array}$ \\
\hline $\begin{array}{l}\text { Panzuto et al, } \\
2003^{11}\end{array}$ & Italy & $\begin{array}{l}\text { Prospective } \\
\text { consecutive }\end{array}$ & 280 & 280 & $41(14.6)$ & $\begin{array}{l}\text { Histology, colonoscopy or double-contrast barium } \\
\text { enema }\end{array}$ \\
\hline $\begin{array}{l}\text { Robertson et al, } \\
2006^{24}\end{array}$ & UK & $\begin{array}{c}\text { Prospective } \\
\text { cohort }\end{array}$ & 604 & 604 & $22(3.6)$ & Cancer registry, flexible sigmoidoscopy \\
\hline $\begin{array}{l}\text { Sanchez et al, } \\
2005^{25}\end{array}$ & Spain & $\begin{array}{c}\text { Prospective } \\
\text { cohort }\end{array}$ & 126 & 104 & $6(5.8)$ & Colonoscopy \\
\hline $\begin{array}{l}\text { Wauters et al, } \\
2000^{26}\end{array}$ & Belgium & $\begin{array}{c}\text { Retrospective } \\
\text { cohort }\end{array}$ & 386 & 386 & 27 (7.0) & Histology, follow-up 18-30 months \\
\hline $\begin{array}{l}\text { Yates et al, } \\
2004^{33}\end{array}$ & UK & $\begin{array}{l}\text { Prospective } \\
\text { randomised }\end{array}$ & 431 & 431 & $37(8.6)$ & Histology \\
\hline
\end{tabular}

